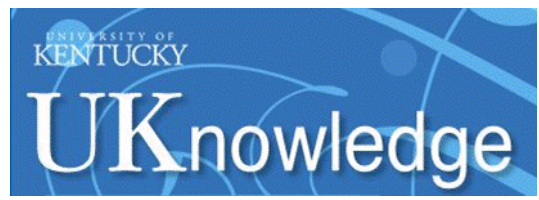

University of Kentucky

UKnowledge

\title{
Recent Advances on Iron Oxide Magnetic Nanoparticles as Sorbents of Organic Pollutants in Water and Wastewater Treatment
}

\author{
Angela M. Gutierrez \\ University of Kentucky, angela.gute@uky.edu \\ Thomas D. Dziubla \\ University of Kentucky, dziubla@engr.uky.edu \\ J. Zach Hilt \\ University of Kentucky, zach.hilt@uky.edu
}

Follow this and additional works at: https://uknowledge.uky.edu/superfund_facpub

Part of the Environmental Health and Protection Commons, Nanoscience and Nanotechnology Commons, Organic Chemicals Commons, and the Water Resource Management Commons

Right click to open a feedback form in a new tab to let us know how this document benefits you.

\section{Repository Citation}

Gutierrez, Angela M.; Dziubla, Thomas D.; and Hilt, J. Zach, "Recent Advances on Iron Oxide Magnetic Nanoparticles as Sorbents of Organic Pollutants in Water and Wastewater Treatment" (2017). Superfund Research Center Faculty Publications. 5.

https://uknowledge.uky.edu/superfund_facpub/5

This Review is brought to you for free and open access by the Superfund Research Center at UKnowledge. It has been accepted for inclusion in Superfund Research Center Faculty Publications by an authorized administrator of UKnowledge. For more information, please contact UKnowledge@lsv.uky.edu. 
Recent Advances on Iron Oxide Magnetic Nanoparticles as Sorbents of Organic Pollutants in Water and Wastewater Treatment

\author{
Digital Object Identifier (DOI) \\ https://doi.org/10.1515/reveh-2016-0063 \\ Notes/Citation Information \\ Published in Reviews on Environmental Health, v. 32, issue 1-2, p. 111-117. \\ (C2017 Walter de Gruyter GmbH, Berlin/Boston.
}

The copyright holder has granted the permission for posting the article here. 


\section{Review}

Angela M. Gutierrez, Thomas D. Dziubla and J. Zach Hilt*

\section{Recent advances on iron oxide magnetic nanoparticles as sorbents of organic pollutants in water and wastewater treatment}

DOI 10.1515/reveh-2016-0063

Received October 19, 2016; accepted January 18, 2017; previously published online February 23, 2017

\begin{abstract}
The constant growth in population worldwide over the past decades continues to put forward the need to provide access to safe, clean water to meet human needs. There is a need for cost-effective technologies for water and wastewater treatment that can meet the global demands and the rigorous water quality standards and at the same maximizing pollutant efficiency removal. Current remediation technologies have failed in keeping up with these factors without becoming cost-prohibitive. Most recently, nanotechnology has been sought as the best alternative to increase access to water supplies by remediating those already contaminated and offering ways to access unconventional sources. The use of iron oxide magnetic nanoparticles as nanoadsorbents has led way to a new class of magnetic separation strategies for water treatment. This review focuses on highlighting some of the most recent advances in core-shell iron oxide magnetic nanoparticles and nanocomposites containing iron oxide nanoparticles currently being developed for water and wastewater treatment of organic pollutants. We discuss the novelty of these novel materials and the insight gained from their advances that can help develop cost-effective reusable technologies for scale-up and commercial use.
\end{abstract}

Keywords: adsorption; environmental remediation; magnetic nanoparticles; nanoadsorbent; water treatment.

\footnotetext{
*Corresponding author: J. Zach Hilt, Superfund Research Center, University of Kentucky, Lexington, KY 40536, USA; and Department of Chemical and Materials Engineering, University of Kentucky, Lexington, KY 40506, USA, Phone: +1 859-257-9844, E-mail: zach.hilt@uky.edu

Angela M. Gutierrez and Thomas D. Dziubla: Superfund Research Center, University of Kentucky, Lexington, KY 40536, USA; and Department of Chemical and Materials Engineering, University of Kentucky, Lexington, KY 40506, USA
}

\section{Introduction}

Water contamination continues to be a major environmental problem worldwide. The United Nations estimates around 3.1\% of deaths worldwide, which is over 1.7 million deaths a year, are caused by unsafe or inadequate access to water (1). Access to safe drinking water is not only a human right but also a necessary factor for economic productivity and technological development. There is an ever increasing need for the global community to develop efficient and affordable technologies to improve the quality of water to meet human and environmental needs.

In recent years, nanomaterial-based technologies have emerged as promising alternatives to current water treatment techniques at lower costs and high efficiencies that can, at the same time, meet the increasingly stringent water quality standards (2-4). Of particular interest among these nanomaterials are iron oxide magnetic nanoparticles (IONPs). In addition to having a high surface area-tovolume ratio, fast kinetics, strong adsorption capacities and high reactivity, IONPs possess the additional property of magnetism. When an external magnetic field is applied to IONPs, they rapidly aggregate together, serving as an easy and cost-effective separation process to extract them from aqueous solutions. Once the magnetic field is removed, the nanoparticles lose their magnetic moment and can easily be redispersed, if they are superparamagnetic. If small enough, IONPs, such as magnetite $\left(\mathrm{Fe}_{3} \mathrm{O}_{4}\right)$ or its oxidation counterpart maghemite $\left(\gamma-\mathrm{Fe}_{2} \mathrm{O}_{3}\right)$, will exhibit superparamagnetic properties. These IONPs can be used directly as nanoadsorbents or as the core component of core-shell structures, where the IONPs function as magnetic separation and the shell provides the desired functionality for pollutant adsorption. Another strategy is to incorporate the IONPs into multiphase materials or nanocomposites (5). Additionally, the purification process to regenerate these materials does not generate secondary or harmful waste and allows for their reuse in environmental remediation (6-10). 
Contamination due to organic pollutants continues to pose a health risk to aquatic environments and humans. Persistent organic pollutants (POPs), such as polycyclic aromatic hydrocarbons (PAHs), polychlorinated biphenyls (PCBs), pesticides, various industrial additives and pharmaceutical and personal care products (PPCPs), are ubiquitous in nature $(11,12)$. POPs have consistently been found in groundwater, drinking water, sewage effluents and sludge, and they can enter the food chain and bioaccumulate to detrimental levels for human health (13, 14). Despite their widespread distribution, most POPs are found at very low concentrations and in complex environmental matrixes making their enrichment, capture and degradation a strenuous task. Traditional treatment techniques are limited to site excavation (15), bacterial remediation in situ (16) and degradation with highly reactive nanoparticles (zero valent iron, bimetallic $\mathrm{Fe}^{0} / \mathrm{Pd}$ or $\mathrm{Au}$ / Pd) to less harmful species $(10,17,18)$.

In this review, we focus on highlighting some of the most recent developments in the application of coreshell IONPs as nanoadsorbents of organic contaminants for water and wastewater treatment. The design of these materials and their current applications are discussed, placing special emphasis on core-shell structures or nanocomposite materials. The environmental behavior, stability and other implications of IONPs use for environmental remediation fall out of the scope of this review and therefore will not be addressed here.

\section{Core-shell IONPs}

Adsorption is the most commonly used technique to remove most organic and inorganic contaminants form water and wastewater treatment (19-22). Conventional adsorbents like activated carbon (AC) are used to trap the contaminant within its pores. Nonetheless, despite the inexpensiveness of the raw materials needed, the energy requirements to obtain high quality $\mathrm{AC}$ and regenerate it after use has proven to have detrimental environmental effects on its own (23). Moreover, the efficacy of such adsorbents is often limited by available surface area or active sites, lack of selectivity and their adsorption kinetics. IONPs, due to their very small size, offer significant improvements in terms of higher surface area and sorption sites and the ability to tune their surface chemistry for enhanced selectivity. Core-shell IONPs consist on an iron magnetic core and a shell materials that comprises the core (outer layer). The shell of these nanoparticles can be organic, inorganic or a combination of both, and its material selections strongly depends upon the end applications and use. The shell tailoring allows for the development of nanocomposite materials that have high affinity for specific contaminants and can be readily used in the environment.

Surfactants are commonly used surface modifiers to help control bare IONP aggregation and interactions (24, 25). Surfactants can be nonionic, amphoteric, cationic or anionic depending on the end application. Recently, magnetic permanently confined micelle arrays (Mag-PCMAs) have been synthesized and have proven to be effective in removing organic contaminants from aqueous solutions $(26,27)$. A silica porous layer is used to confine the cationic surfactant micelles into the mesopores preventing loss during subsequent use. Huang et al. (28) demonstrated high adsorption rate and capacity for three different industrial effluents and PPCPs (methyl orange, sulfamethoxazole and gemfibrozil) as well as two different PAHs (acenaphthene and phenanrtene). By adding a micelle swelling agent during synthesis and then removing it Huang et al. (28), were able to increase the pore volume and surface area of the Mag-PCMAs, thus increasing their sorption capacity and diffusion rate. The methyl orange removal efficiency and the visual color change due to fast sorption kinetics of three different Mag-PCMAs synthesized with different amount of swelling agent is shown in Figure 1A,B. Here, it can be seen the rapid adsorption in the first $30 \mathrm{~min}$, achieving a 98\% removal efficiency. Further studies showed that pollutant sorption formed a monolayer dominated by hydrophobic interactions between the surfactants and the molecule in question. Overall, Mag-PCMAs show promise as high efficiency sorbents for organic pollutant with large pore sizes and more porous channels than those synthesized in other ways, hence providing a sustainable fast and reusable water treatment technique that can be extended and scaled-up to continuous batch reactors.

$\beta$-Cyclodextrin ( $\beta$-CD) is a seven glucose cyclic oligosaccharide that is well known for its capacity to form hostguest complexes with a variety of molecules due to the formation of cavities with an external hydrophilic surface, an internal hydrophobic pocket and a specific diameter $(29,30)$. Thanks to these specific host-guest interactions, $\beta$-CD has been widely used as a surface modifier of IONPs specifically for the capture of some hydrophobic organic contaminants, such as PCBs, and has gained interests in environmental remediation (31-33). In the past year, Wang et al. (34) developed a core-shell magnetic nanoparticle consisting of a magnetite core and a silica bonded $\beta$-cyclodextrin layer $\left(\mathrm{Fe}_{3} \mathrm{O}_{4} @ \beta\right.$-CD) capable of adsorbing PCB-28 and PCB-52 in aqueous solutions, as shown in Figure 1C. The adsorption capacities of $\mathrm{Fe}_{3} \mathrm{O}_{4} @ \beta$-CD for 

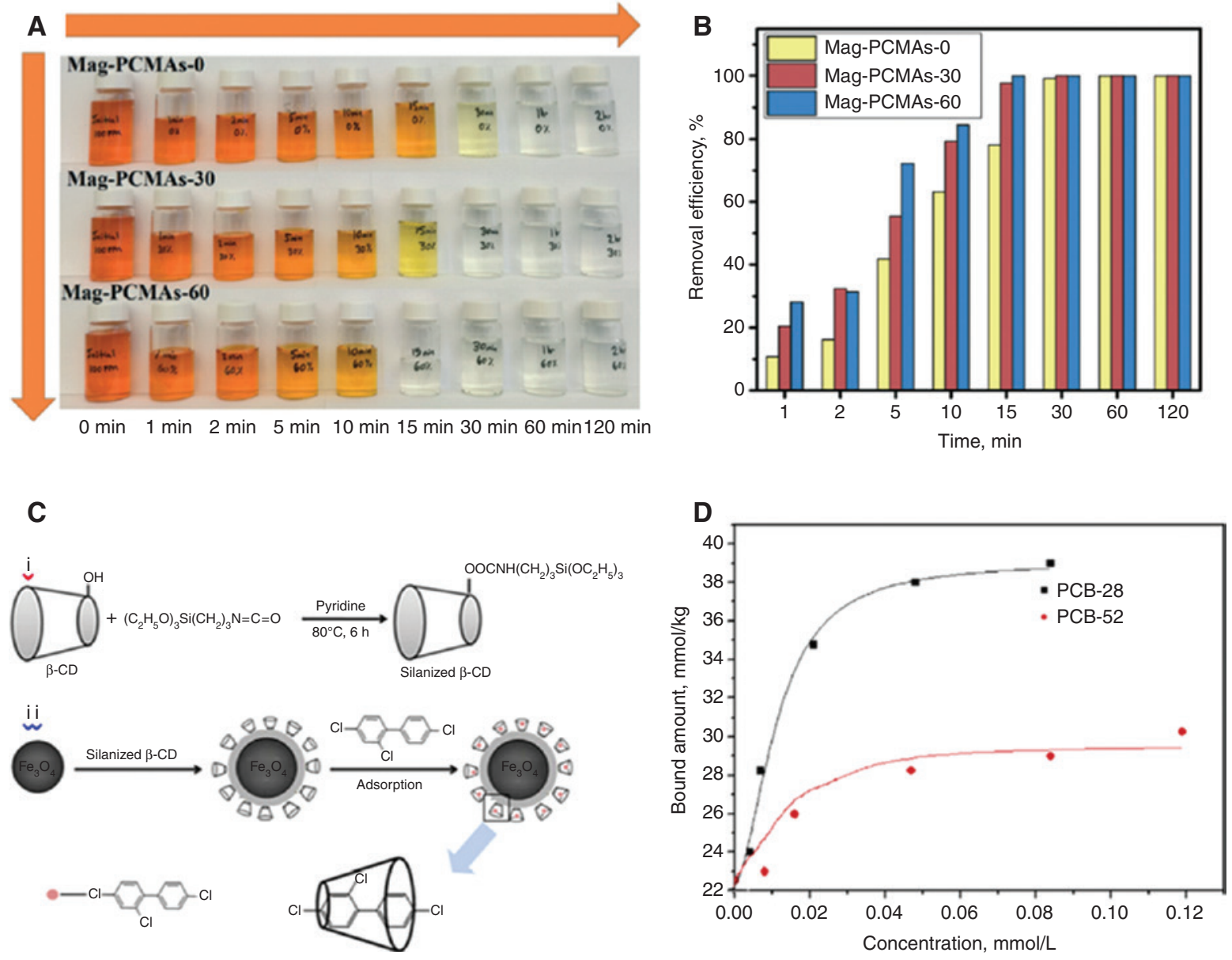

Figure 1: Methyl orange sorption onto Mag-PCMAs (A) visualization of color change across time sequence and (B) removal efficiency versus time. (C) Schematic diagram of (i) the synthesis of silanized $\beta-C D$ and (ii) the formation of $\mathrm{Fe}_{2} \mathrm{O}_{3} @ \beta$-CD. (D) Adsorption isotherms of PCB-28 and PCB-52 bound by $\mathrm{Fe}_{2} \mathrm{O}_{3} @ \beta-\mathrm{CD}$.

the PCB congeners were studied in water and incubated for $24 \mathrm{~h}$, after which the nanoparticles were isolated with a magnet and UV absorbance measurements were used to determine the concentration of the residual solution. It was demonstrated that the $\beta$-CD can increase the binding capacity almost three-fold when compared to the magnetite core. The PCB inclusion within the $\mathrm{Fe}_{3} \mathrm{O}_{4} @ \beta$-CD cavity was $1: 1$, and due to the specific diameter of the cavity, the specific adsorption for PCB-28 was a little higher than that for PCB-52. The Langmuir isotherms for PCB-28 and PCB-52 are shown in Figure 1D, where the absorptive capacities of 40.01 and $30.32 \mathrm{mmol} / \mathrm{kg}$, respectively, can be seen. The functionalized core-shell nanoparticle developed by Wang et al. (27) can effectively be used to concentrate organic contaminants from water, easily separated from the contamination source and readily extended and applied for environmental remediation.

Recently, our group has described a novel and versatile one step coprecipitation synthesis methodology of curcumin stabilized iron oxide magnetic nanoparticles (C-IO MNPs), shown in Figure 2A, that can potentially be used in environmental remediation, biomedical and catalysis applications (35). Curcumin is a naturally occurring antioxidant and polyphenol found in the Indian spice turmeric, with a high content of aromatic groups in its molecular structure $(36,37)$. The presence of these groups offers the possibility of interaction through pi-pi sticking with similar molecules, such as PCBs, in a variety of environments. Bhandari et al. (35) demonstrated successful incorporation of the curcumin onto the surface of the IONPs, representing around $10-12 \%$ in mass of the nanoparticle's weight. The C-IO MNPs showed a 10-fold increase in safe administration limits compared to uncoated IONPs when incubated for $24 \mathrm{~h}$ with human umbilical vein endothelial cells (HUVECs), thanks to the antioxidant response of curcumin. Additionally, when these cells were exposed to PCB 126 in the presence of C-IO MNPs, a protective effect against this inflammatory agent was seen. Figure 2B shows 


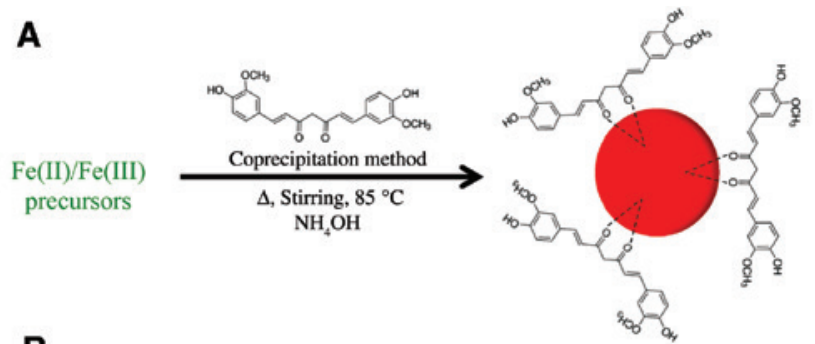

B

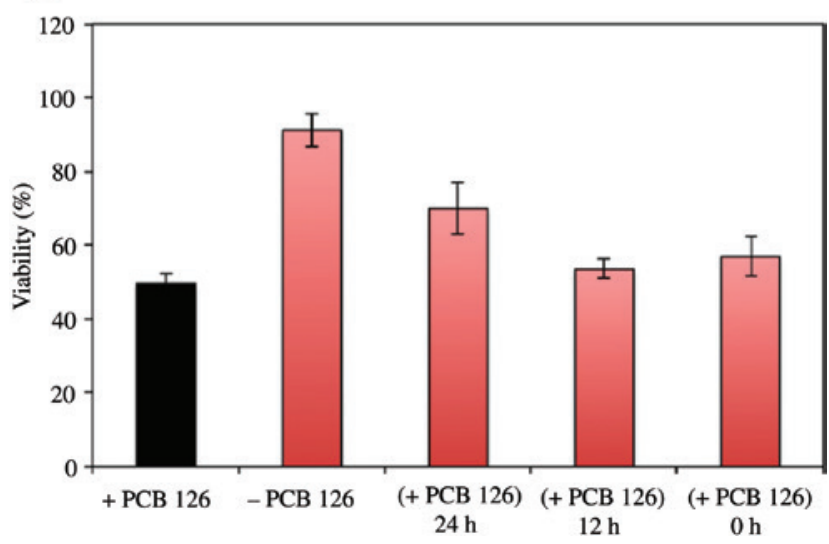

Figure 2: Synthesis method for curcumin functionalized magnetic iron oxide nanoparticles. Here the ammonium hydroxide reduces the iron salts to produce the magnetic iron oxide nanoparticle (red sphere), followed by the formation of a curcumin shell on the IONPS through electrostatic interactions (A). Protection against PCB 126 induced inflammation. HUVECs preincubated with $10 \mu \mathrm{g} / \mathrm{mL}$ curcumin iron oxide nanoparticles for 0,12 and $24 \mathrm{~h}$ followed by $24-\mathrm{h}$ exposure to $50 \mu \mathrm{M}$ PCB126 (B).

the $\%$ viability of HUVECs preincubated with $10 \mu \mathrm{g} / \mathrm{mL}$ of C-IO MNPs for 0, 12 and $24 \mathrm{~h}$ followed by a 24-h exposure to $50 \mu \mathrm{M}$ PCB 126. It can be seen that the antioxidant effect of curcumin protects the cells against PCB 126 showing a greater cell viability between treated and nontreated cells. This protection can be attributed to the interactions between PCB 126 and curcumin, most likely through pi-pi stacking, which reduced the bioavailability of this stressor and the cell burden in general. The results from this study can be further extended to environmental burden and reduced bioavailability of organic contaminants such as PCBs in contaminated water sources due to the aforementioned pi-pi stacking interactions that can be employed to capture/adsorb and sense these pollutants.

\section{IONP nanocomposites}

Another approach to developing high efficiency nanomaterials for treatment of POPs in water consists on using IONPs in a confined micro- or macroscale support, which allows for the nanoparticles to still exhibit their reactivity while being complemented by the adsorbent properties of the accompanying materials. One such material is chitosan (CS). CS is a natural material that is hydrophilic and contains active sites along its polymeric chain due to the presence of $-\mathrm{NH}_{2}$ groups. Because of these properties, CS has recently been regarded as one of the most promising biosorbents for water and wastewater treatment for negatively charged contaminants $(38,39)$. A very successful nanocomposite fabricated using CS, lignocellulose fibers (LCF) and IONPs has been developed by Zhou et al. (40) for biosorptive removal of acidic azo dyes. First, the CS decorated LCF was prepared via surface deposition crosslinking and then magnetized through blending in an aqueous solution containing IONPs allowing for spontaneous adherence, as seen in Figure 3A. The magnetic CS/ LCF ( $m$ CS/LCF) was used to adsorb acid red 18 (AR 18) as model azo dye from water at different $\mathrm{pH}$, ionic strength and temperature. As expected, the adsorption of azo dyes onto $\mathrm{mCS} / \mathrm{LCF}$ is highly $\mathrm{pH}$ dependent due to the protonation of the amino groups $\left(-\mathrm{NH}_{3}{ }^{+}\right)$in $\mathrm{CS}$ at lower $\mathrm{pH}$, which increases electrostatic interactions between the negatively charged AR 18 anions and the positively charged adsorption sites. Additionally, the adsorption isotherms of $m \mathrm{CS} / \mathrm{LCF}$ indicate a homogeneous surface where the adsorption process is govern by intraparticle diffusion. As the AR 18 molecule is adsorbed onto the exterior surface of $m \mathrm{CS} / \mathrm{LCF}$, the available sites diminish until saturation is reached. From this point on, the AR 18 molecules need to overcome the diffusion resistance of the saturated surface to diffuse into the pores, resulting on a longer time needed to reach equilibrium. Hence, the two distinct slopes observed for the Weber-Morris diffusion model plot (Figure 3B) of AR 18 adsorption on mCS/LCF. Furthermore, Zhou et al. (40) demonstrated that the removal of AR 18 remained at around $99.68 \%$ throughout 10 consecutive cycles. Overall, the newly developed $m$ CS/LCF nanocomposite offers a facile and reusable biosorbent that can be easily separated from the adsorption medium by means of applying a magnetic field, all while obtaining remarkably high adsorption capacities, $1181 \mathrm{mg} / \mathrm{g}$ compared to $828.1 \mathrm{mg} / \mathrm{g}$ for pure nanochitosan.

Similarly, Arya and Phillip (41) have recently designed a nanocomposite containing clay, activated carbon, chitosan and IONPs for the adsorption of pharmaceuticals in water. Although activated carbon itself has long been considered one of the best available control technologies for a wide range of pollutants, the removal efficiencies reported for hydrophilic pollutants tend to be smaller (42). Therefore, with this new magnetic clay composite, the ability to remove cationic or anionic, and hydrophilic or hydrophobic contaminants was achieved. The selected pharmaceuticals 
A

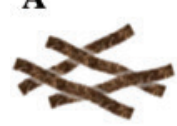

(LCF)

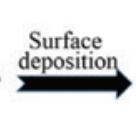

$\longrightarrow$
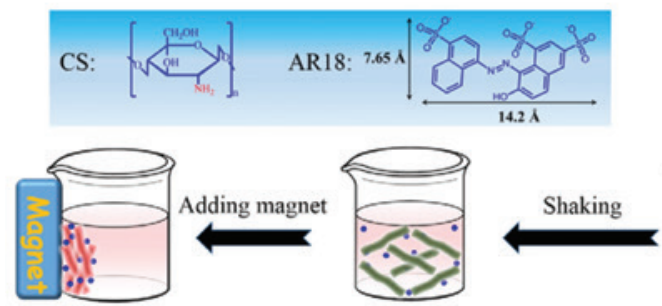

C

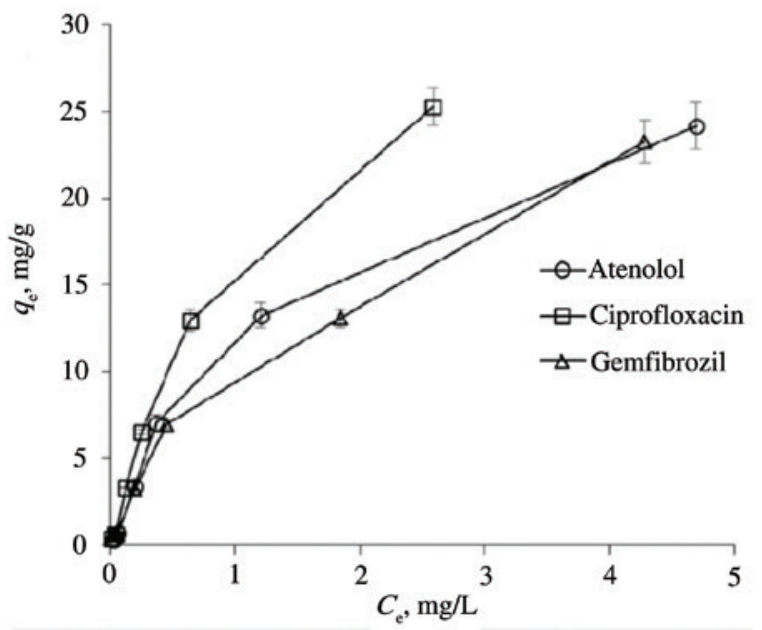

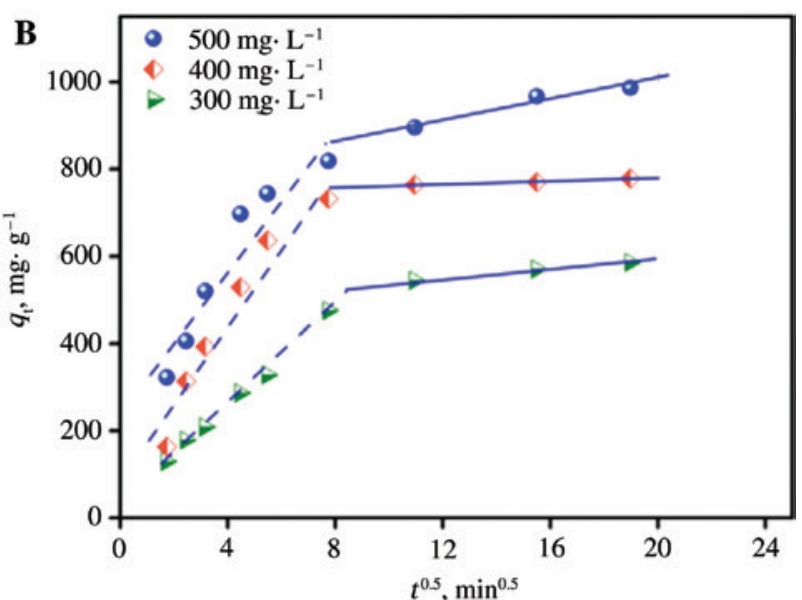

D

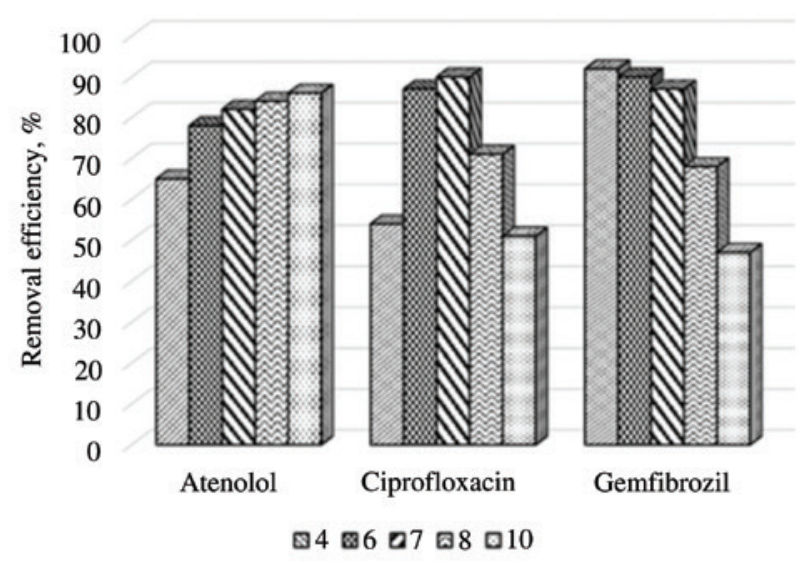

Figure 3: Principle and process of magnetic chitosan/lignocellulose fibers ( $m$ CS/LCF) formation and application for acid red 18 (AR18) removal (A). Webber-Morris diffusion model plots for the adsorption of AR18 onto $m C S / L C F$ (B). Sorption of three different pharmaceuticals at different initial pharmaceutical concentrations (C) and the effect of $\mathrm{pH}$ on their adsorption onto a novel nanocomposite composed of clay, activated carbon, CS and iron nanoparticles.

for the adsorption studies utilized by Arya and Phillip were atenolol (beta blocker), ciprofloxacin (antibiotic) and gemfibrozil (lipid regulator), of which the first two are hydrophilic. A high removal for atenolol and ciprofloxacin was observed, $85 \%$ and $95 \%$, respectively. This was attributed to the hydrophilic nature of these compounds and of the CS-clay composite, as well as to cation exchange between the cationic form of the pharmaceuticals and the magnetic composite. Correspondingly, a high removal of gemfibrozil, $90 \%$, was seen and attributed to the hydrophobic nature of the pharmaceutical and the activated carbon, as well as surface interactions with CS. Figure $3 \mathrm{C}$ shows the equilibrium sorption of the pharmaceuticals to the nanocomposite at different initial concentrations. It can be observed that the maximum adsorption capacity was higher for ciprofloxacin $(39.1 \mathrm{mg} / \mathrm{g})$ than for gemfibrozil $(24.8 \mathrm{mg} / \mathrm{g})$ and atenolol $(15.7 \mathrm{mg} / \mathrm{g})$. Additionally, the equilibrium data shed insight into the highly heterogeneous nature of the nanocomposite, which favored the adsorption of the pharmaceuticals used. The adsorption process was discovered to be occurring through ion exchange rather than phisy-sorption. This discovery was corroborated by Figure $3 \mathrm{D}$, where it was seen that adsorption of these pollutants was also highly $\mathrm{pH}$ dependent, similar to the findings from Zhou et al. (40), and the $\mathrm{pH}$ determines the ionization of the pharmaceuticals. At lower $\mathrm{pH}$, the adsorption of anionic pollutants, like gemfibrozil, will be favored because of the presence of protonated amine groups on the surface of the clay and CS, as well as the presence of the IONPs, which contribute to an overall positive charge on the nanocomposite. Finally, the nanocomposite developed by Arya and Phillip proves to be a promising adsorbent for pharmaceuticals in water and wastewater treatment that is reusable and easy to use. 


\section{Conclusion}

The present review has examined the most recent developments of iron-based nanoparticle technologies used for water and wastewater treatment. The unique properties of iron nanoparticles, specifically its magnetic characteristics, have proven to be advantageous for a variety of adsorbents and present great opportunities to keep revolutionizing the available techniques for organic pollutant remediation. Although many of the technologies being developed are still in the laboratory research stage, they have shown success in adsorbing pollutants from water under different $\mathrm{pH}$, temperature, ionic strength and organic matter conditions with high adsorption capacities and good reusability, showing progress towards pilot testing, upscaling and even commercialization.

The challenges faced by water and wastewater treatment IONP technologies rely mainly on the potential for human and environmental risk associated with their use, life cycle and disposal. The implications of these nanomaterials, however, can prove to be only temporary as more research is conducted in the area. Another important factor is the cost of making an applying these technologies, which has recently seen a decrease due to the use of readily available and low cost precursor materials such as iron, clay, silica and CS, to name a few. In addition, there is a need for comparative testing to be adopted by the research community that allows comparison between different adsorbent materials and performance so that developments in the area can move forward at a faster pace.

The key towards a successful iron oxide nanoadsorbents that meet the stringent environmental regulations lies in developing a high surface area nanocomposite with increased reactivity that does not sacrifice the magnetic properties of its components, all while minimizing the costs of the entire production process. The future for nanoadsorbents based on iron oxide nanoparticles looks very promising not only for removal of organic pollutants from water and wastewater but for other contaminants and from other contaminated media.

\section{Author Statement}

Research funding: The project was supported by grant number P42ES007380 from the National Institute of Environmental Health Sciences (NIEHS). Conflict of interest: Authors state no conflict of interest. The content is solely the responsibility of the authors and does not necessarily represent the official views of the National Institute of Environmental Health Sciences. Informed consent: Informed consent is not applicable. Ethical approval: The conducted research is not related to either human or animals use.

\section{References}

1. World Health Organization. Progress on sanitation and drinking water. 2015 Update and MDG Assessment. Available at: http:// www.unicef.org/publications/index_82419.html.

2. Masciangioli T, Zhang WX. Environmental technologies at the nanoscale. Environ Sci Technol 2003;37(5):102A-8A.

3. Qu X, Brame J, Li Q, Alvarez PJJ. Nanotechnology for a safe and sustainable water supply: enabling integrated water treatment and reuse. Acc Chem Res 2013;46(3):834-43.

4. Zhao Z, Lan J, Li G, Jiang G. Iron-based magnetic nanomaterials on wastewater treatment. In: Reisner, DE, Pradeep T, editors. Aquananotechnology: global prospects. Baton Rouge: CRC Press, 2015:265-91.

5. Ajayan PS, Schadler L, Braun PV, editors. Nanocomposite science and technology. Weinheim: Wiley-VCH, 2003:239.

6. Huang YK, Keller AA. EDTA functionalized magnetic nanoparticle sorbents for cadmium and lead contaminated water treatment. Water Res 2015;80:159-68.

7. Huang Y, Keller AA. Magnetic nanoparticle adsorbents for emerging organic contaminants. Sustainable Chem Eng 2013;1(7):731-6.

8. Tang SC, Lo IM. Magnetic nanoparticles: essential factors for sustaianble environmental applications. Water Res 2013;47(8):2613-32.

9. Xu JS, Zhu YJ. $\gamma$-Fe203 and Fe304 magnetic hierarchically nanostructured hollow microspheres: preparation, formation mechanism, magnetic property, and application in water treatment. J Colloid Interface Sci 2012;385(1):58-65.

10. Geng Z, Lin Y, Yu X, Shen Q, Ma L, et al. Highly efficient dye adsorption and removal: a functional hybrid of reduced graphene oxide-Fe304 nanoparticles as an easily regenerative adsorbent. J Mater Chemi 2012;22:3527-35.

11. Richardson ST, Ternes TA. Water analysis: emerging contaminants and current issues. Anal Chem 2014;86(6): 2813-48.

12. Jones KC, de Voogt P. Persistent organic pollutants (POPs): state of the science. Environ Pollution 1999;100(1-3):209-21.

13. Dang VD, Walter DM, Lee CM. Historical changes in polychlorinated biphenyls contaminated sediments. Am J Environ Sci 2012;8(1):11-5.

14. Hopf NB, Ruder AM, Succop P. Background levels of polychlorinated biphenyls in the U.S. population. Sci Total Environ 2009;407(24):6109-19.

15. Gomes HI, Dias-Ferreira C, Ribeiro AB. Overview of in situ and ex situ remediation technologies for PCB-contaminated soils and sediments and obstacles for full-scale application. Sci Total Environ 2013;445-446:237-60.

16. Schwarts E, Scow KM. Repeated inoculation as a strategy for the remediation of low concentrations of phenanthrene in soil. Biodegradation 2001;12(3):201-7. 
17. Lowry GV. Nanomaterials for groundwater remediation. In: WeisnerMR, Bottero J, editors. Evironmental nanotechnoogy. New York: McGraw Hill Companies, 2007:297-336.

18. Liu Y, Choi H, Dionysiou D, Lowry GV. Trichloroethane hydrodechlorination in water by highly disordered monometallic nanoiron. Chem Mater 2005;17(21):5315-22.

19. Beless B, Rifi H, Rodrigues DF. Efficacy of carbonaceous materials for sorbing polychlorinated biphenyls from aqueous solution. Environ Sci Technol 2014;48(17):10372-9.

20. Bystrzejewski M, Pyrzyndka K, Huczko A, Lange H. Carbonencapsulated magnetic nanoparticles as separable and mobile sorbents of heavy metal ions from aqueous solutions. Carbon 2009;47(4):1201-6.

21. Ormad MP, Miguel N, Claver A, Matesanz JM, Ovelleiro JL. Pesticides removal in the process of drinking water production. Chemosphere 2008;71(1):97-106.

22. Liu JF, Zhao ZS, Jiang GB. Coating Fe304 magnetic nanoparticles with humic acid for high efficient removal of heavy metals in water. Environ Sci Technol 2008;42(19):6949-54.

23. Vince F, Aoustin A, Breant P, Marechal F. LCA tool for the environmental evaluation of potable water production. Desalination 2008;220(1-3):37-45.

24. Basnet M, Ghoshal S, Tufenkji N. Rhamnolipid biosurfactant and soy protein act as effective stabilizers in the aggregation and transport of palladium-doped zerovalent iron nanoparticles in saturated porous media. Environ Sci Technol 2013;47(23):13355-64.

25. Saleh N, Sirk N, Liu Y, Phenrat T, Dufour B, et al. Surface modifications enhance nanoiron transport and NAPL targeting in saturated porous media. Environ Eng 2007;24(1):45-7.

26. Clark KK, Keller AA. Adsorption of perchlorate and other oxyanions onto magnetic permanently confined micelle arrays (Mag-PCMAs). Water Res 2012;46(3):635-44.

27. Wang P, Shi Q, Shi Y, Clark KK, Stucky GD, et al. Magnetic permanently confined micelle arrays for treating hydrophobic organic compound contamination. J Am Chem Soc 2009;131(1):182-8.

28. Huang Y, Fulton AN, Keller AA. Optimization of porous structure of superparamagnetic nanoparticle adsorbents for higher and faster removal of emerging organic contaminants and PAHs. Environ Sci: Water Res Technol 2016;2(3):521-8.

29. Martin Del Valle EM. Cyclodextrins and their uses: a review. Process Biochem 2004;39(9):1033-46.

30. Fava F, Bertin L, Fedi S, Zannoni D. Methyl- $\beta$-cyclodextrinenhanced solubilization and aerobic biodegradation of polychlorinated biphenyls in two aged-contaminated soils. Biotechnol Bioeng 2003;81(4):381-90.

31. Alsbaiee A, Smith BJ, Xiao L, Ling X, Helvling DE, et al. Rapid removal of organic micropollutants from water by a porous B-cyclodextrin polymer. Nature 2016;529:190-4.

32. Li J, Chen C, Zaho Y, Hu J, Shao D, et al. Synthesis of water-dispersible Fe304@ $\beta$-cyclodextrin by plasma-induced grafting technique for pollutant treatment. Chem Eng J 2013;229:296-303.

33. Landy D, Mallard I, Ponchel A, Monflier E, Fourmentin S. Remediation technologies using cyclodextrins: an overview. Environ Chem Let 2012;10(3):225-37.

34. Wang M, Liu P, Wang Y, Zhou D, Ma C, et al. Core-shell superparamagnetic Fe304@ $\beta$-CD composites for host-guest adsorption of polychlorinated biphenyls (PCBs). J Colloid Interface Sci 2015;447:1-7.

35. Bhandari R, Gupta P, Dziubla T, Hilt JZ. Single step synthesis, characterization and applications of curcumin functionalized iron oxide magnetic nanoparticles. Mater Sci Eng C 2016;67:59-64.

36. Wilken R, Veena MS, Wang MB, Srivatsan ES. Curcumin: a review of anti-cancer properties and therapeutic activity in head and neck squamous cell carcinoma. Mol Cancer 2011;10(1):12.

37. Aggarwal BB, Shishodia S. Molecular targets of dietary agents for prevention and therapy of cacner. Bioochem Phamrmacol 2006;71(10):1397-421.

38. Wan Ngah WS, Teong LC, Hanafiah MAKM. Adsorption of dyes and heavy metal ions by chitosan composites: a review. Carbohydrate Polymers 2011;83(1):1446-56.

39. Ahmaruzzaman Md. Adsorption of phenolic compounds on low-cost adsorbents: a review. Adv Colloids Interface Sci 2008;143(1-2):48-67.

40. Zhou CG, Gao Q, Wang S, Gong YS, Xia KS, et al. Remarkable performance of magnetized chitosan-decorated lignocellulose fiber towards biosorptive removal of acidic azo colorant from aqueous environment. Reactive Functional Polymers 2016;100:97-106.

41. Arya V, Phillip, L. Adsorption of pharmaceuticals in water using Fe304 coated polymer clay composite. Microporous Mesoporous Mats 2016;232:273-80.

42. Redding AM, Cannon FS, Snyder SA, VanderfordBJ. A QSAR-like analysis of the adsorption of endocrine disrupting compounds, pharmaceuticals, and personal care products on modified activated carbons. Water Res 2009;43(15):3849-61. 